\title{
AP physics: A closer look
}

\author{
Eric W. Burkholder@ \\ Department of Physics, Stanford University, Stanford, California 94305, USA
}

(Received 6 September 2020; accepted 9 February 2021; published 15 March 2021)

\begin{abstract}
Previously, we had reported on the relationship between AP physics experience and exam scores, and student scores on the Force and Motion Conceptual Evaluation and in an introductory calculus-based mechanics course [E. W. Burkholder and C. E. Wieman, Phys. Rev. Phys. Educ. Res. 15, 020117 (2019)]. Two limitations to our previous work were that we aggregated data from algebra-based mechanics (AP physics 1) and calculus-based mechanics (AP physics C - Mechanics) courses, and that only $25 \%$ of the students who took AP physics reported their scores to the university; we addressed these limitations here. We found that there was no reporting bias in these scores for either AP course. We found that AP physics 1 (AP1) exam scores were predictive of students' FMCE scores while AP physics C (APC) exam scores were not - this is consistent with our previous findings. We found that APC exam scores were more predictive of course grades in physics 1, but that students who scored a 5 on the AP1 exam also had high grades in physics 1, despite it being a calculus-based course. These results disagree with our previous findings that AP exam scores were not correlated with final exam scores after controlling for SAT or ACT math scores, likely due to the variability in course final exams from year to year. Though these results are for a single, highly selective university, they provide some key insights to educators about the value of AP courses. One important implication is that students who score a 5 on the AP1 exam can likely receive credit for the calculus-based introductory course, increasing access to higher level physics courses for students whose high schools do not have access to APC courses.
\end{abstract}

DOI: 10.1103/PhysRevPhysEducRes.17.013101

\section{INTRODUCTION}

Each year, roughly 300000 high school students take an advanced placement (AP) physics course [1]. These are algebra-based and calculus-based courses in introductory mechanics and electricity and magnetism that are widely accepted as substitutes for university physics courses [2]. Despite their popularity, we know of only two studies linking AP physics experience and AP physics exam scores to other measures of physics performance [3-4].

In a prior study, we examined the variation in Force and Motion Conceptual Evaluation (FMCE) [5] scores by students' prior physics experience [4]. This study used data collected from the physics 1 course at Stanford University, and from the office of institutional research. Our research questions were whether FMCE scores varied by students' prior physics experience, whether AP physics exam scores were correlated with FMCE scores, and whether AP exam scores were correlated with physics 1 performance, where physics 1 is a standard calculusbased introductory mechanics course for scientists and

Published by the American Physical Society under the terms of the Creative Commons Attribution 4.0 International license. Further distribution of this work must maintain attribution to the author(s) and the published article's title, journal citation, and DOI. engineers. We found that all students with prior physics experience scored higher than students with no prior physics on the FMCE, but found that differences between types of prior physics experience were not significant. Furthermore, we found that the correlation between AP physics experience (a binary variable indicating whether a student had taken AP physics or not) and FMCE scores was smaller than the correlation between SAT or ACT math scores and FMCE scores. Finally, we found that AP exam score was not a statistically significant predictor of FMCE score or physics 1 final exam score once we controlled for the effects of SAT or ACT math scores [which we took to be a crude proxy of general college science, technology, engineering, and mathematics (STEM) preparation] [4].

In aggregate, these results suggested that taking an AP physics course was a poorer-than-expected predictor of conceptual understanding of physics (as measured by FMCE scores), and introductory physics course performance (as measured by physics 1 final exam scores). Indeed, the data suggested that students who take AP physics perform better on other measures of physics performance not because of the AP courses themselves, but because students who take AP physics generally have higher levels of general academic preparation (as measured by SAT or ACT math score).

In this study, we address two important limitations of our previous work. (i) In our prior study we did 
TABLE I. Data on how many students take AP1 and APC, what fraction of those students do not take the AP exam, and average AP exam scores and standard deviations for both exams.

\begin{tabular}{lccccc}
\hline \hline Test & $\begin{array}{c}\text { Fraction of students } \\
\text { who take AP course }\end{array}$ & $\begin{array}{c}\text { Fraction of AP students } \\
\text { not taking test }\end{array}$ & $\begin{array}{c}\text { Score reported } \\
\text { to university } \\
\text { (from [4]) }\end{array}$ & $\begin{array}{c}\text { Self-reported } \\
\text { score }\end{array}$ & $\begin{array}{c}\text { Difference between } \\
\text { university and } \\
\text { self-report }\end{array}$ \\
\hline AP1 & $32 \%(N=117)$ & $17 \%(N=20)$ & $4.1 \pm 0.90$ & $3.8 \pm 1.0$ & $p=0.48$ \\
APC & $18 \%(N=66)$ & $19 \%(N=12)$ & $4.1 \pm 0.77$ & $3.9 \pm 1.0$ & $p=0.42$ \\
\hline \hline
\end{tabular}

not have sufficient data to distinguish between AP physics 1 [algebra-based mechanics (AP1)] and AP physics $\mathrm{C}-$ Mechanics [calculus-based mechanics (APC)]. These two courses are very different, and it is thus possible that the correlations we observed would be different if we analyzed the two courses separately. (ii) In the previous study we received AP scores from the office of institutional research, but by surveying the students, found that only $25 \%$ of the students who took an AP course reported their scores to the university. This is likely due to the strong disincentives to claim AP credit at the university in question. It was not clear whether these students took the AP exam and did not report their scores, or did not take the AP exam at all, because there is no published data looking at reporting bias in AP physics scores. Furthermore, it was not clear whether this distribution of AP scores was skewed higher than the true distribution of AP scores.

Our research questions for this study were the following:

1 . Is there any reporting bias in AP physics scores reported to a highly selective private research university?

2. Are the correlations between AP exam scores and other measures of physics performance different for AP1 and APC?

\section{METHODS}

During the winter of 2020, we collected data from 410 students enrolled in the introductory calculus-based mechanics course for scientists and engineers ("physics 1 ") at a highly selective private research university in the western United States. This course followed the text Young and Freedman [6], and covered kinematics, forces and torques, Newton's laws, conservation of momentum, angular momentum, and conservation of energy. The course had three lectures and one recitation section per week. The lectures were traditional with some use of clicker questions and peer instruction [7]. The recitation sections focused on reviewing lecture material, with time dedicated to solving problems from Tutorials in Introductory Physics [8]. The course had two midterm exams and one final exam that comprised $80 \%$ of students' final grades. The remaining $20 \%$ of students' grades came from weekly problem-sets participation. For all students, we obtained math SAT or ACT percentile scores and physics 1 course grades from the office of institutional research.
During the first recitation section, the FMCE and a background survey were administered as a zero-stakes assessment. 366 of the 410 students completed the assessment. The survey covered students' physics and math backgrounds, social-psychological factors, and students' ideas about group work. For this study, the relevant data from this survey is what prior physics courses students had taken, and, if they had taken AP physics, whether they had taken the AP exam, and what score they received on the AP exam (self-reported). 32\% of the 366 students had taken AP1 and 18\% had taken APC (Table I). The remaining students had a high school physics course (42\%) or no prior physics course $(8 \%)$.

For analysis, we converted students' prior physics experience to a three-level categorical variable. The reference level was students with no AP physics, and the other two levels were students who had taken AP1 and APC. Students' course grades were converted from letter grades to a 4.0 scale, and then those scores were converted to $z$ scores. Students' SAT or ACT math percentile and FMCE scores were also converted to $z$ scores. To analyze the relationships between these variables, we used multiple linear regression, which tests a linear relationship between the outcome variables (either FMCE score or course grade) and the predictors (AP physics experience, AP exam scores, or SAT or ACT math scores). Visual examination of scatter plots did not suggest nonlinear relationships. Multiple linear regression was the appropriate tool in this case because we were testing multiple correlations at the same time and trying to judge the relative effect sizes of different factors.

\section{RESULTS}

First, we examined reporting bias in AP physics scores (Table I). In our previous work, the average AP1 score

TABLE II. Regression model of FMCE scores on students' prior physics experience and students' SAT or ACT math scores. $* p<0.05, * * p<0.01, * * * p<0.001$.

\begin{tabular}{lcc}
\hline \hline & Model 1 & Model 2 \\
\hline Intercept & $-0.18^{*}(0.072)$ & $-0.19^{* *}(0.069)$ \\
AP1 & $0.26^{*}(0.12)$ & $0.31^{* *}(0.11)$ \\
APC & $0.54 * *(0.14)$ & $0.50^{* * *}(0.13)$ \\
SAT or ACT math score & & $0.28^{* * *(0.049)}$ \\
Adj. R squared & 0.038 & 0.11 \\
Power & 0.94 & 0.99 \\
\hline \hline
\end{tabular}


TABLE III. Regression model of FMCE scores on students' AP physics exam scores and SAT or ACT math scores. * $p<0.05, * *$ $p<0.01, * * * p<0.001$.

\begin{tabular}{lcccc}
\hline \hline & Model 1 & Model 2 & Model 3 & Model 4 \\
\hline Intercept & $0.22^{* *}(0.071)$ & $0.58 * * *(0.11)$ & $0.22 * *(0.071)$ & $0.48 * * *(0.12)$ \\
AP1 score & $0.52 * * *(0.071)$ & & $0.50 * * *(0.081)$ & $0.0092(0.11)$ \\
APC score & & $0.040(0.11)$ & $0.037(0.073)$ & $0.35 \dagger(0.19)$ \\
SAT or ACT math score & 0.33 & & 0.32 & 0.027 \\
Adj. R squared & 1.0 & -0.016 & 1.0 & 0.20 \\
Power & & 0.05 & & 0.00 \\
\hline \hline
\end{tabular}

reported to the university was 4.1 [standard deviations (s.d.) $=0.90]$. The average AP1 score reported by students in 2020 was 3.8 (s.d. $=1.0$ ). This difference was not statistically significant (Mann-Whitney U-test, $p=0.48$ ). The average APC score reported to the university in Ref. [4] was 4.1 (s.d. $=0.77$ ) and the average self-reported score in 2020 was 3.9 (s.d. $=1.0$ ). This difference was not statistically significant $(p=0.42) .17 \%$ of students who took AP1 and $19 \%$ of students who took APC chose not to take the AP exam.

Next, we examined FMCE scores and how they differed by students' prior physics experience. The model we tested was

$$
\mathrm{FMCE}=b_{0}+b_{\mathrm{Exp}} \text { Experience }+b_{\mathrm{SAT}} \mathrm{SAT},
$$

where "Experience" was the categorical variable described previously, and SAT was students' SAT or ACT math percentile scores. In model 1 of Table II, we assumed $b_{\mathrm{SAT}}=0$. Students who did not take any AP physics course

TABLE IV. Regression model of physics 1 course grades on students' prior physics experience and students' SAT or ACT math scores. * $p<0.05$, ** $p<0.01$, *** $p<0.001$.

\begin{tabular}{lcc}
\hline \hline & Model 1 & Model 2 \\
\hline Intercept & $-0.084(0.066)$ & $-0.087(0.062)$ \\
AP1 & $0.085(0.12)$ & $0.13(0.11)$ \\
APC & $0.35^{* *}(0.13)$ & $0.30^{*}(0.13)$ \\
SAT or ACT math score & & $0.33^{* * *(0.047)}$ \\
Adj. R squared & 0.012 & 0.12 \\
Power & 0.45 & 0.99 \\
\hline \hline
\end{tabular}

scored 0.18 s.d. below average. Students who took AP1 scored 0.26 s.d. higher than students who took no AP physics, and students who took APC scored 0.54 standard deviations higher than students who took no AP physics (Table II, model 1). The difference between APC and AP1 was marginally significant $(p=0.074)$. These regression coefficients were similar when we added in SAT or ACT math scores (Table II, model 2), and the SAT coefficient was similar in size to the coefficient we reported previously [9].

We next investigated the correlation between AP exam scores and FMCE scores. The model we tested was

$$
\mathrm{FMCE}=b_{0}+b_{\mathrm{AP}} \mathrm{AP} \text { Score }+b_{\mathrm{SAT}} \mathrm{SAT},
$$

where "AP Score" was a student's score on the AP exam. In models 1 and 3, we used AP1 scores, while in models 2 and 4 we used APC scores. In models 1 and 2, we assumed $b_{\mathrm{SAT}}=0$. (see Table II). We found a strong correlation between AP1 score and FMCE score $\left(b_{\mathrm{AP}}=0.52\right)$. The correlation between APC score and FMCE score was not statistically significant (Table III, model 2). These correlations were similar when we added SAT or ACT math scores to the model (Table III, models 3 and 4). SAT or ACT math scores were strongly correlated with AP1 scores (hence the small SAT coefficient in model 3) but were not correlated with APC exam scores, indicating a ceiling effect in the APC population-most SAT scores were in the 98th-100th percentile.

We next investigated differences in course grades for students with different AP physics experience (Table IV). We found that students who took AP1 had course grades that were 0.085 s.d. higher than students who took no AP

TABLE V. Regression model of physics 1 course grades on students' AP physics exam scores and SAT or ACT math scores. $\dagger p<0.10, * p<0.05, * * p<0.01, * * * p<0.001$.

\begin{tabular}{lcccc}
\hline \hline & Model 1 & Model 2 & Model 3 & Model 4 \\
\hline Intercept & $0.13 \dagger(0.070)$ & $0.32 * * *(0.055)$ & $0.14 *(0.067)$ & $0.24 * * *(0.055)$ \\
AP1 score & $0.41 * *(0.071)$ & & $0.29 * * *(0.076)$ & $0.32 * * *(0.051)$ \\
APC score & & $0.34 * *(0.055)$ & $0.23 * *(0.069)$ & $0.30 * * *(0.084)$ \\
SAT or ACT math score & 0.23 & 0.40 & 0.30 & 0.50 \\
Adj. R squared & 0.99 & 0.99 & 0.99 & 0.99 \\
Power & & & & \\
\hline \hline
\end{tabular}


physics, but this difference was not significant. Students who took APC scored 0.35 s.d. higher than students with no AP physics experience. These differences were similar after adding the effects of SAT or ACT math score (Table IV, model 2). The coefficient for SAT or ACT math score was similar to previous investigations [9].

Finally, we examined the correlation between AP exam scores and course grades (Table V). We found a strong correlation between AP1 score and course grade $\left(b_{\mathrm{AP}}=0.41\right)$. There was also a strong correlation between APC score and course grade $\left(b_{\mathrm{AP}}=0.34\right)$. These correlations remained strong once we added in SAT or ACT math scores (models 3 and 4). The regression coefficients for AP exam scores in models 3 and 4 were similar to the coefficients for FMCE prescores in Ref. [9], and the SAT or ACT math score coefficients were also similar to those in Ref. [9].

\section{DISCUSSION}

Some of the notable findings here agree with our previous study and others do not. The first notable finding is that there is no reporting bias in AP exam scores in this population-the distributions of scores reported to the university and those self-reported by students are indistinguishable. We expected self-reported scores to be lower because the university only awards credit for scores of 5 , but that is not the case. It is possible that the self-reported scores are not accurate representations of students' actual performance but given the importance of AP scores in admissions to elite institutions like the one studied here it seems plausible that students would remember their scores. The background survey given to students was administered as part of a zero-stakes assessment, so it seems unlikely that students would artificially inflate their scores.

We also found that over $80 \%$ of students who take an AP course take the AP exam, though only $25 \%$ of students who take an AP course report their scores to the university. We posit that students do not report their AP scores because of the strong disincentive to claim credit for AP physics at this university, but future investigations should verify this. This suggests that universities who accept a wider range of AP scores may see higher rates of score reporting than the institution studied here.

The relationship between AP physics experience and FMCE scores is consistent with our previous findings. Students who take any AP physics perform better than students who do not take AP physics, but the difference in conceptual understanding between students who take AP1 and APC is small (the difference in average scores was only 4\%). This is qualitatively consistent with our previous finding. Furthermore, AP physics experience remains correlated with FMCE score after controlling for SAT or ACT math score, as reported previously.

It is noteworthy that only AP1 exam scores are correlated with FMCE scores. The lack of correlation between APC scores and FMCE scores is not due to a ceiling effect in the FMCE score distribution for APC students, suggesting that the APC exam is not measuring students' conceptual understanding of force and motion. Conversations with AP consultants suggest that the algebra-based exam focuses more on students conceptual understanding, while the calculus-based exam focuses more on calculations. For example, an AP1 question might ask students to predict what will happen to an object sliding along a frictional surface if the mass is doubled, while an APC question might ask about 1D kinematics with nonconstant acceleration. This difference between the two exams also explains why we previously saw a small correlation between AP exam score and FMCE score. Indeed, if we combine AP1 scores and APC scores in this sample, the regression coefficient on AP score is 0.098 and the coefficient on SAT or ACT math score is 0.37 , almost identical to what we found previously (see Table III in Ref. [4]).

The effects of AP physics experience on course grades align with expectations. Students who take APC perform better in a calculus-based mechanics course than students who take AP1 or no AP course. In addition, we find that APC exam score is a better predictor of course grade than AP1 score, which follows conventional logic. However, it is worth noting that the correlation between AP1 score and course grade is still strong, indicating that students who score well on the AP1 exam will do well in the calculusbased physics 1 . In this sample, the difference between students who score a 5 on AP1 versus APC is only 0.12 standard deviations.

The previous result is markedly different from our previous work, where we found no correlation between AP physics exam scores and final exam grades after controlling for SAT or ACT math scores. One plausible explanation for this difference is that the constructs measured by course final exams change each year. It is possible that, in 2018, the alignment between the AP physics exam and course final exam happened to be poor, but the alignment in 2020 is better. Course grades consist of multiple exam scores and homework scores and may thus be more complete measures of physics performance and more likely to align with the content covered by the AP exam in a given year.

\section{CONCLUSION}

This work provides greater detail on the relationship between AP physics experience and performance, and conceptual understanding of physics and course performance. Our findings suggest that the AP1 exam is measuring students' conceptual understanding of physics, while the APC exam is not. On the other hand, the APC exam is a better predictor of introductory course performance than the AP1 exam. Our findings also suggest that AP physics exam score is a better predictor of introductory 
course performance than previously indicated, and even suggests that students who get a 5 on the algebra-based AP physics exam can get an A in a calculus-based introductory course.

One important implication for educators is that students who score a 5 on AP1 may have a better conceptual understanding of physics than students who take APC, and even have similar course performance to students who score a 5 on the APC exam. Departments can thus award students course credit for high scores on either AP physics exam, without worrying that the students who took algebra-based physics did not learn as much as students who took calculus-based physics.

We note that this work is still limited by our use of data from a single, highly selective institution. The AP score distributions are likely much higher here than at many universities, and thus the predictive power of AP scores may be limited in these samples, which may particularly bias our findings about the correlation between AP scores and FMCE scores. Additionally, physics 1 courses may vary between institutions, so how well AP physics scores predict physics 1 performance is likely institution dependent.
[1] The College Board, Score distributions (2018), retrieved from https://apscore.collegeboard.org/scores/about-ap-scores/ score-distributions/.

[2] The College Board, AP course description (2014), retrieved from https://apstudent.collegeboard.org/apcourse/ap-physicsc-mechanics/course-details.

[3] N. T. Belcher, Modeling instruction in APC: Mechanics and electricity and magnetism, Ph.D. thesis, University of South Carolina, 2017.

[4] E. W. Burkholder and C. E. Wieman, What are AP physics courses teaching and the AP physics exam measuring?, Phys. Rev. Phys. Educ. Res. 15, 020117 (2019).

[5] R. Thornton and D. Sokoloff, Assessing student learning of Newton's laws: The Force and Motion Conceptual
Evaluation and the Evaluation of Active Learning Laboratory and Lecture Curricula, Am. J. Phys. 66, 338 (1998).

[6] H. D. Young and R. A. Freedman, University Physics with Modern Physics, 14th ed. (Pearson Boston, 2015).

[7] C. H. Crouch and E. Mazur, Peer instruction: Ten years of experience and results, Am. J. Phys. 69, 970 (2001).

[8] L. C. McDermott and P. S. Shaffer, Tutorials in Introductory Physics (Prentice Hall, Upper Saddle River, NJ, 2002).

[9] S. Salehi, E. W. Burkholder, G. P. Lepage, S. J. Pollock, and C. E. Wieman, Demographic gaps or preparation gaps?: The large impact of incoming preparation on performance of students in introductory physics, Phys. Rev. Phys. Educ. Res. 15, 020114 (2019). 